\title{
The Influence of Colour Solution of the ETICS Surface on its Thermal Exposition
}

\author{
PASEK $\operatorname{Jan}^{1, a^{*}}$ \\ ${ }^{1}$ University of West Bohemia, Faculty of Applied Sciences, Department of Mechanics, \\ Univerzitni 8, 30614 Pilsen, Czech Republic \\ apasek@kme.zcu.cz
}

\begin{abstract}
Keywords: Colour shades of ETICS façade surface, absorption of light, HBW coefficient, TSR coefficient, surface temperature, dynamics of surface temperature changes, risk of ETICS damage.
\end{abstract}

\begin{abstract}
The colour solution of the surface of the façade is one of the basic factors for reaching the requested aesthetic and architectonic expression of the building. This target is sometimes reached by using very saturated tones of colours or changing dark and light tones on one façade. Such solution is often risky as one of the characteristics of dark colour tones is high absorption of solar and scattered radiation. Its thermal compound causes warming of the outer layers of the façade proportionally to the surface colour saturation. This consequence is very serious especially for thinlayer plaster of external thermal insulation composite systems (ETICS) immediately exposed to dynamic effect of external environment temperature changes, which can be even increased by inappropriate colour solution of the ETICS surface. This paper focuses on evaluation of the influence of ETICS surface colouring on the thermal load.
\end{abstract}

\section{Introduction}

So far the influence of the saturation of the façade surface colour on absorption of solar radiation has been mostly expressed by HBW coefficient (Hellbezugswert - coefficient of light radiation reflectance). This parameter is not completely objective, because in the spectral range of the light radiation only certain part of the thermal radiation is distributed to the surroundings. Light (visible) radiation corresponding with the spectral sensitivity of human eye can be found within the wavelength ranging from 0.38 to $0.78 \mu \mathrm{m}$. Infrared (thermal) radiation lies in the adjacent interval of the electromagnetic spectrum in the wavelength ranging from 0.78 to $1000 \mu \mathrm{m}$. Although based on Wien's Displacement Law the visible radiation corresponding with the temperature of the Sun (circa $6000 \mathrm{~K}$ ) is the carrier of a significant part of the thermal energy incident on the Earth that makes only circa $40 \%$ of the total thermal radiation radiated in the whole spectrum of the solar radiation. Therefore the parameter TSR (Total Solar Reflectance) has been introduced [1]. This parameter takes into account the total thermal output generated on all wavelengths of the solar source radiation.

The human eye is able to distinguish lighter and darker tones of the colours based on the ability of these colours to absorb the visible radiation. Darker tones (more saturated colours) absorb more light (and reflect less of it) while it is vice versa with the lighter tones. The tones perceivable by the human eye as darker show at the same time also higher ability to absorb the thermal radiation, therefore they get warmer in the sunshine. The ability of the body surface to absorb or reflect the radiation does not directly depend on the colour tone but on its saturation, glossiness, and surface structure. That is why the absorption of thermal solar radiation is better expressed by the coefficient TSR than HBW. The problem is that there is no direct dependency between TSR and HBW, the value of HBW might be higher or lower than TSR. Depending on the composition of the surface layer and colour tone, it is possible that even several different values of HBW can correspond with one TSR value and vice versa. 
The coefficient HBW, which has been used in the construction practice so far is a percentage formulation of the share of reflected component of light radiation on the total visible radiation incident on surface of the sunlit façade. Mathematically it is possible to express it by Eq. 1:

$$
\mathrm{HBW}=\rho .100(\%)
$$

while reflectivity $\rho$ is for non-translucent solid objects an addition of the emissivity to value 1 - see Eq. 2.

$$
\rho+\varepsilon+\tau=1(-)
$$

where $1 \ldots . .100 \%$ of visible radiation incident on the surface of the object;

$\rho$...... proportion of radiation reflected from the object surface (surface reflectance $=$ reflectivity);

$\varepsilon \ldots$.... proportion of radiation absorbed by the object (surface absorption = emissivity);

$\tau$..... proportion of radiation penetrating the object (permeability of the object $=$ transmissivity); most of the solid objects show $\tau=0$.

\section{Evaluation of the Dependency of ETICS Surface Warming on Coefficient HBW}

The suppliers of certified contact insulation systems ETICS usually recommend using colour tones of the thin-layer plaster with HBW value $=25$ or higher. However the use of tones with value HBW less than 20 is not so uncommon. It is possible to deduce from the Eq. 1 and 2 that the surface of the peripheral wall plaster with colour tone of $\mathrm{HBW}=25$ reflects $25 \%$ of the incident light radiation back to the surroundings and absorbs $75 \%$ of it. Lower value of HBW on the other hand means the higher percentage of absorbed light radiation which thermal compound therefore more warms the sunlit surface. It is the same in the case of TSR values, which have been gradually introduced into the practice. Besides other negative consequences warming of ETICS constructions causes increase of dilatation and mechanical stress mainly on the surface layers of the insulation systems and further in combination with other influences it increases the risk of their damage.

In last years there was a research of the influence of coefficient HBW on surface temperatures of sunlit ETICS surfaces. The experiment was performed using chosen samples provided by the company Baumit Ltd. in series Granopor and ArtLine. For the basis they used boards of façade EPS with thickness $100 \mathrm{~mm}$ on which they applied formation of reinforced armour layer and thin-layer plaster with fraction $1.5 \mathrm{~mm}$ in 24 colour tones. The coefficient HBW of the used samples had values between 11 to 87; the values of coefficients TSR were not stated. Arrangement of the samples ETICS into the test matrix is shown in the Fig. 1; the characteristics of the thin-layer plaster of the samples are in Table 1. The testing matrix was placed on unshielded vertical south-west façade.

\begin{tabular}{|c|c|c|c|c|c|c|c|}
\hline $\begin{array}{c}\text { Granopor } \\
\text { Top Style } \\
3271-\text { K 1,5 } \\
\text { HBW 14 }\end{array}$ & $\begin{array}{c}\text { Granopor } \\
\text { Top Paradise } \\
3363 \text { - K 1,5 } \\
\text { HBW 45 }\end{array}$ & $\begin{array}{c}\text { Granopor } \\
\text { Top Touch } \\
3163 \text { - K 1,5 } \\
\text { HBW 25 }\end{array}$ & $\begin{array}{c}\text { Granopor } \\
\text { Top History } \\
3121 \text { - K 1,5 } \\
\text { HBW 16 }\end{array}$ & $\begin{array}{c}\text { Granopor } \\
\text { Top Smart } \\
3301 \text { - K 1,5 } \\
\text { HBW 21 }\end{array}$ & $\begin{array}{c}\text { Granopor } \\
\text { Top Family } \\
3111-\text { K 1,5 } \\
\text { HBW 20 }\end{array}$ & $\begin{array}{c}\text { Granopor } \\
\text { Top Aqua } \\
3201 \text { - K 1,5 } \\
\text { HBW 24 }\end{array}$ & $\begin{array}{c}\text { Granopor } \\
\text { Top Ocean } \\
3221 \text { - K 1,5 } \\
\text { HBW 30 }\end{array}$ \\
\hline $\begin{array}{c}\text { ArtLine } \\
\text { Top Orange } \\
7 \text { - K 1,5 } \\
\text { HBW } 25 \\
\end{array}$ & $\begin{array}{c}\text { ArtLine } \\
\text { Top Blue } \\
7-\text { K 1,5 } \\
\text { HBW 13 } \\
\end{array}$ & $\begin{array}{c}\text { Granopor } \\
\text { Top Home } \\
3073 \text { - K 1,5 } \\
\text { HBW } 38 \\
\end{array}$ & $\begin{array}{c}\text { Granopor } \\
\text { Top Life } \\
3337-\text { K 1,5 } \\
\text { HBW 77 } \\
\end{array}$ & $\begin{array}{c}\text { Granopor } \\
\text { Top Basic } \\
3393 \text { - K 1,5 } \\
\text { HBW 11 }\end{array}$ & $\begin{array}{c}\text { Granopor } \\
\text { Top Princess } \\
3009-\text { K 1,5 } \\
\text { HBW 87 }\end{array}$ & $\begin{array}{c}\text { ArtLine } \\
\text { Top Blue } \\
1-\text { K } 1,5 \\
\text { HBW 15 } \\
\end{array}$ & $\begin{array}{c}\text { ArtLine } \\
\text { Top Red } \\
5-\text { K 1,5 } \\
\text { HBW 12 } \\
\end{array}$ \\
\hline $\begin{array}{c}\text { Granopor } \\
\text { Top Ice } \\
3191 \text { - K 1,5 } \\
\text { HBW } 28\end{array}$ & $\begin{array}{c}\text { Granopor } \\
\text { Top Free } \\
3181 \text { - K 1,5 } \\
\text { HBW } 29\end{array}$ & $\begin{array}{c}\text { Granopor } \\
\text { Top Flirt } \\
3151-\text { K 1,5 } \\
\text { HBW 17 }\end{array}$ & $\begin{array}{c}\text { Granopor } \\
\text { Top History } \\
3123-\text { K 1,5 } \\
\text { HBW 26 }\end{array}$ & $\begin{array}{c}\text { Granopor } \\
\text { Top Harmony } \\
3097 \text { - K 1,5 } \\
\text { HBW } 65\end{array}$ & $\begin{array}{c}\text { Granopor } \\
\text { Top Tradition } \\
3101-\text { K 1,5 } \\
\text { HBW 22 }\end{array}$ & $\begin{array}{c}\text { Granopor } \\
\text { Top Sacret } \\
3135 \text { - K 1,5 } \\
\text { HBW 56 }\end{array}$ & $\begin{array}{c}\text { Granopor } \\
\text { Top Home } \\
3071-\text { K 1,5 } \\
\text { HBW } 27\end{array}$ \\
\hline
\end{tabular}

Table 1. Characteristics of thin-layer façade of the tested samples acc. Fig. 1. 

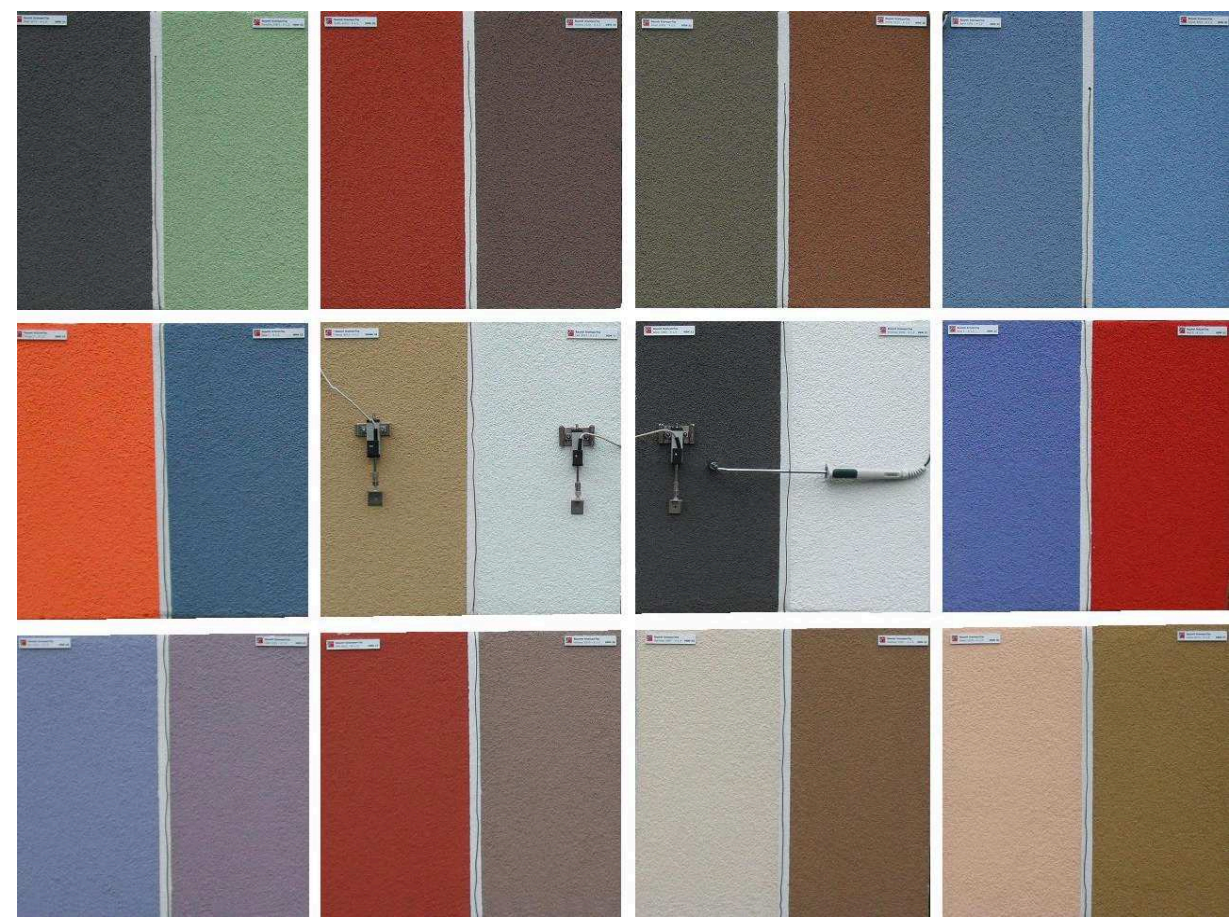

Fig. 1. Arrangement of tested samples ETICS into the testing patterns.

Some of the assorted tones of the samples of test matrix were fitted with sensors for contact measuring of surface temperature and sensors for measuring the temperature and humidity of the surroundings environment in distance $100 \mathrm{~mm}$ of the ETICS surface. All sensors were attached to a logger, which had been saving the measured data in 10 minutes intervals for longer period of time. The whole test formation of the samples was at the same time recorded by thermocamera with data saving interval 20 minutes. An example of the surface temperatures arrangement is shown in Fig. 2.

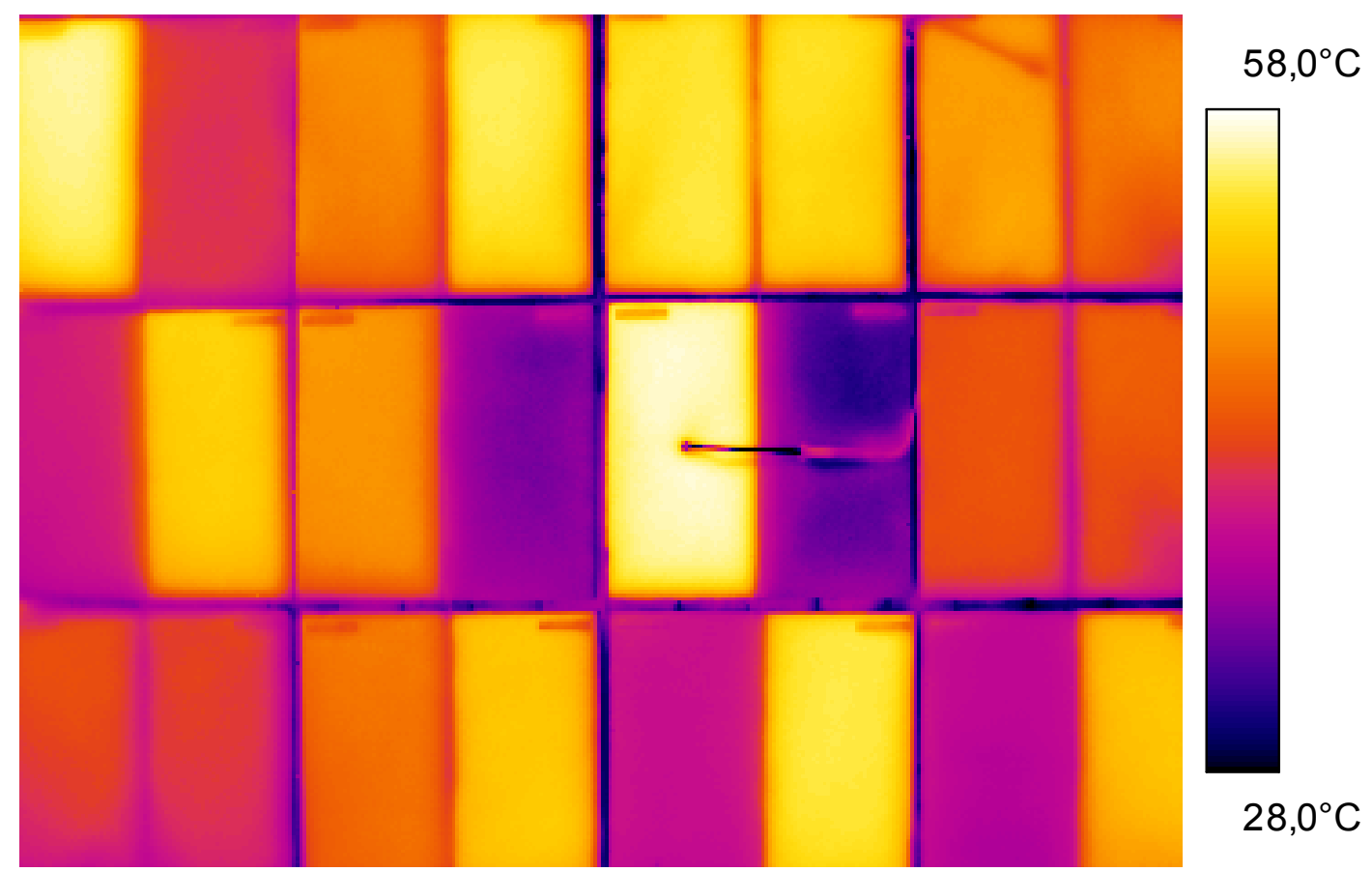

Fig. 2. Example of surface temperatures arrangement of tested ETICS samples.

The maximum values of the measured surface temperatures especially at samples with $\mathrm{HBW}=$ 11 to 15 were nearly $70{ }^{\circ} \mathrm{C}$ while at samples with $\mathrm{HBW}$ higher than 50 they were almost $20^{\circ} \mathrm{C}$ 
lower. However during the years when the intensity of solar radiation is higher than in the interest period or when the surface is older and covered with dirt it is possible to expect also the surface temperatures to be higher. In case of using foam polystyrene as thermal insulation ETICS it is possible to expect its damage by high temperatures. The highest measured values of the surface temperature are shown in the Fig. 3. The significantly different values of the surface temperatures found at samples Granopor and ArtLine with approximately the same HBW values are caused by higher value of TSR for ArtLine series.

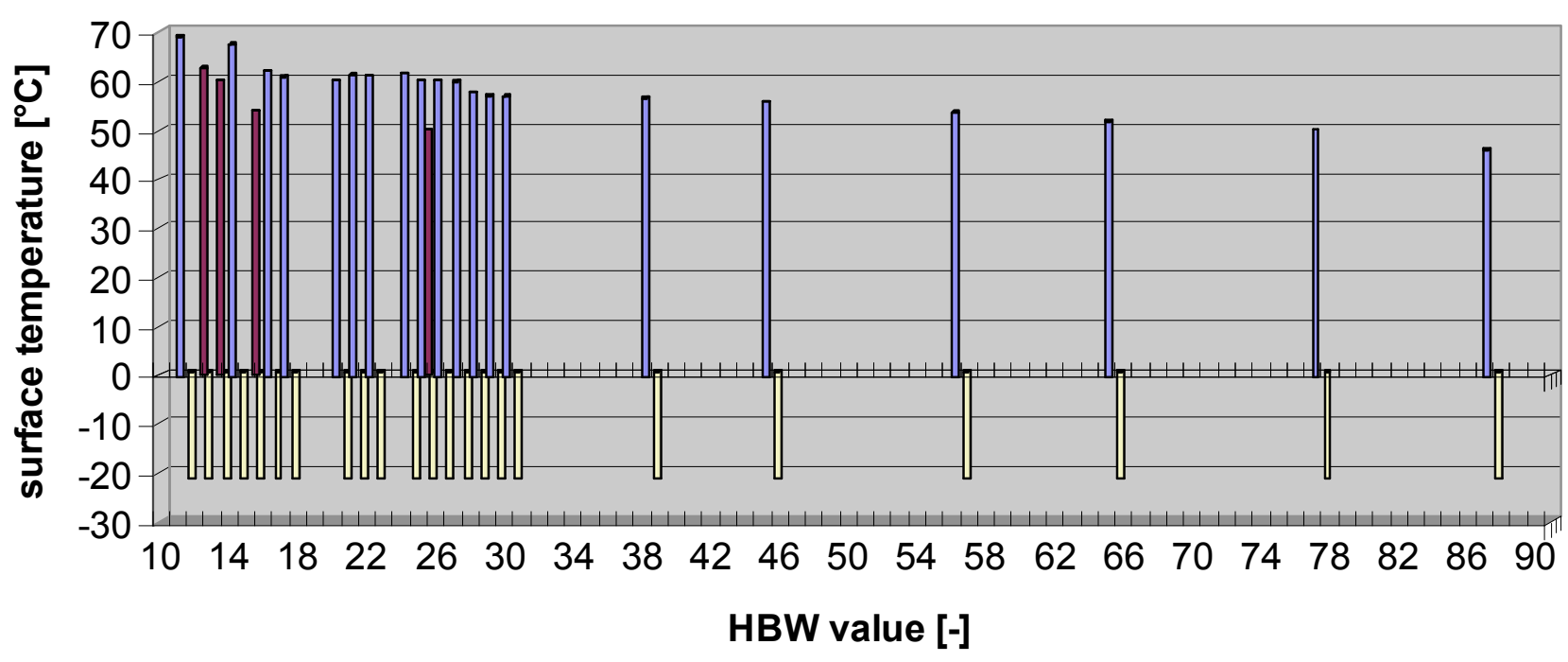

$\square$ Granopor-summer $\quad \square$ ArtLine - summer $\quad \square$ winter

Fig. 3. Dependency of maximal values of experimentally measures surface temperatures on HBW of the surface.

\section{Dynamics of Thermal Changes on the ETICS Surface}

Fast temperature changes, which take place not only during summer when there are storms and the warmed surface is fiercely cooled by torrential rain proved to be significant in terms of dynamics of temperature changes on ETICS surface. Quite dynamic temperature changes also happen during transition periods of the year (autumn, spring). During this time the sun is relatively low on the horizon, its radiation reaches the surface of vertical façades in very effective direction, and warms them intensively to temperatures higher then $50{ }^{\circ} \mathrm{C}$ (see Fig. 4). After the sunset the thin-layer façade cools very fast because of the cold surrounding air, low temperature inertia of the whole formation ETICS, and incidence of the low potential radiation of the cool sky. In framework of evaluation of the dynamics of surface temperatures decrease the following temperature changes were detected on the sample with $\mathrm{HBW}=11$ :

- during 10 minutes decrease of up to $16^{\circ} \mathrm{C}$;

- during 30 minutes decrease of up to $22^{\circ} \mathrm{C}$;

- during 1 hours decrease of up to $29^{\circ} \mathrm{C}$;

- during 6 hours decrease of up to $56^{\circ} \mathrm{C}$.

During the measuring on sample with $\mathrm{HBW}=11$ a temperature fluctuation more than $62{ }^{\circ} \mathrm{C}$ (see Fig. 4) was measured in a 24-hour cycle and within a 12-month period the width of the temperature interval was measured to $89{ }^{\circ} \mathrm{C}$ (the lowest surface temperatures dropped during the winter time below $-21{ }^{\circ} \mathrm{C}$ ). Both these temperatures are circa $20{ }^{\circ} \mathrm{C}$ higher than the range of the surface temperatures to which the samples with HBW higher than 56 are exposed. Some already performed researches (e.g. [2], [3], [4]) proved that the temperature changes significantly exceeding the range $60{ }^{\circ} \mathrm{C}$ during an annual cycle pose high risk of development of cracks in surface thin-layer façade ETICS. 


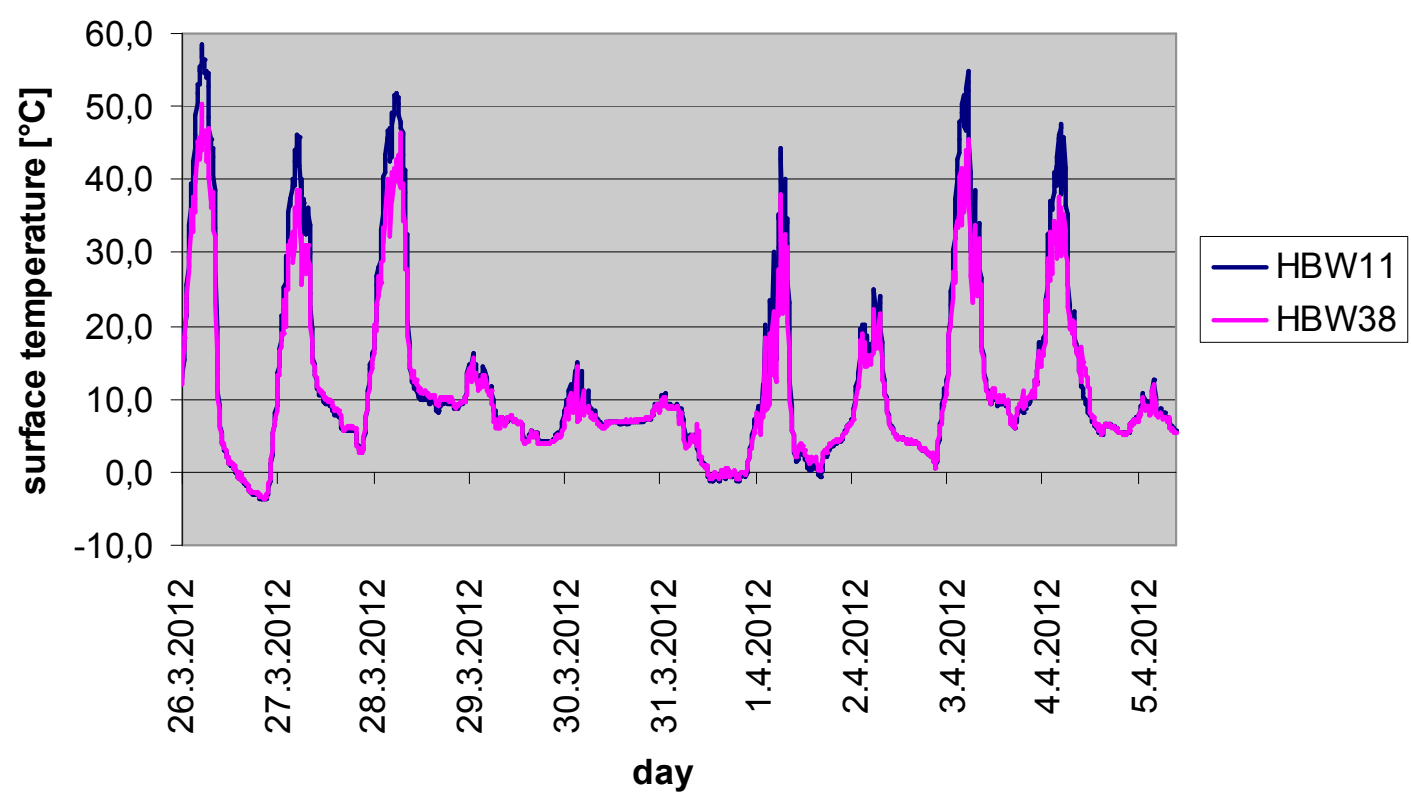

Fig. 4. Graph showing development of contact-measured surface temperatures on samples Baumit Granopor Top Basic 3393 - K 1,5 (HBW = 11) and Granopor Top Home 3073 - K 1,5 (HBW = 38) during the period from $26^{\text {th }}$ March, 2012, 10.00 am to $5^{\text {th }}$ April, 2012, $7.30 \mathrm{pm}$.

\section{Summary}

Using dark colours on ETICS finish with low values of HBW or TSR has several negative consequences. Among the most important there is excessive warming of the ETICS surface causing increased dilatation and stress of the surface thin-layer façade. That leads to increased risk and to actual cases of disruption of the layer and further decrease of durability and reliability of the whole ETICS formation.

The measurements performed within the framework of the long-term research showed that in case of ETICS it is appropriate to move the recommended limit of minimal HBW from so far used value 25 to at least 30 in way to provide sufficient reliability of the contact insulation. At the same time it is desirable to better specify the influence of solar radiation on the thermal exposition of ETICS by more detailed research and by replacing the currently used coefficient HBW with TSR.

\section{Acknowledgements}

The research work was supported by the Project SGS-2013-036.

\section{References}

[1] Thermal insulation systems Baumit - Technological prescription, Baumit Ltd., March 2013.

[2] J. Witzany, T. Cejka, R. Zigler, J. Pasek, Risk factors of the reliability of contact thermal insulation systems of prefabricated buildings, in: Thermal protection of buildings, Prague, 2/11 (2008), pp. 37-44.

[3] J. Pasek, Analysis of factors affecting stress of thin-layer plaster of contact thermal insulation systems of prefabricated panel buildings, in: Reliability, optimization and durability of building materials and structures, Czech Technical University in Prague, 2007, pp. 31-42.

[4] J. Pasek, Analysis of stress of thin-layer plaster of contact thermal insulation systems of prefabricated panel buildings, in: Failures and reconstruction of peripheral claddings and roofs, Technical University in Kosice, Faculty of Civil Engineering, 2007, pp. 83-88. 